УДК 811.112.2’42:070

ББК 81.432.4

DOI: https://doi.org/10.17308/lic.2021.2/3420

\title{
МЕТАФОРИЧЕСКАЯ РЕПРЕЗЕНТАЦИЯ ПАНДЕМИИ СОVID-19 В ТЕКСТАХ НЕМЕЦКИХ СМИ
}

\author{
М. А. Шаманская
}

Иркутский государственный университет

\section{METAPHORICAL REPRESENTATION OF THE COVID-19 PANDEMIC IN GERMAN MASS MEDIA TEXTS}

\author{
M. A. Shamanskaya \\ Irkutsk State University
}

\begin{abstract}
Аннотация: в статье анализируется метафора как языковое средство репрезентации пандемии коронавируса в немеиком дискурсе СМИ. Целью исследования является выявление особенностей процесса метафоризачии, затрагивающего новое и значимое явление общественной жизни. Объект изучения метафоры, используюшиеся в текстах новостных сообщений и аналитических обзоров электронного издания Spiegel Online, посвященных теме пандемии. Материалом послужил корпус примеров объемом 103 текста, полученный методом сплошной выборки. Теоретически и методологически настоящая работа базируется на теории метафорического моделирования. В исследовании использован следующий комплекс методов: метод лингвокультурного анализа, метод компонентного анализа, метод контекстуального и стилистического анализа. Рассмотрение фактологического материала позволило нам сделать вывод о том, что метафоры являются важным средством выражения нового знания о ситуачии пандемии. Тематика пандемии подвергается активной метафоризаџии в текстах современных немецких средств массовой информации. В рассматриваемых примерах коронавирус метафорически представлен как самостоятельно действующая сила, вступающая во взаимодействие и коммуникацию с людьми и проявляющсая инициативу в названном взаимодействии. Заболеванию приписывается активная роль в различных общественных процессах. Метафоры конструируют образ пандемии как образ врага; соответственно, противостояние COVID-19 и человечества описывается в терминах борьбы и войны. В свою очередь, понятийная область болезни служит сферой-источником для создания метафор, репрезентирующих значимые явления современной жизни. Исследование метафорического представления актуальной ситуащии пандемии может внести определенный вклад в понимание роли языка как одного из средств кониептуализации действительности.
\end{abstract}

Ключевые слова: метафора, средства массовой информации, немецкие СМИ, пандемия, коронавирус, COVID-19.

Abstract: the article analyzes the metaphor as the linguistic tool of representation of the coronavirus pandemic in German media discourse. The goal of this research is to reveal the peculiarities of the process of metaphorization in relation to the new and significant factor of public life. The object of the study are metaphors used in the texts of the Spiegel Online informing about the pandemic. The material of the study is the corpus of 103 texts obtained using the method of continuous sampling. The theoretical and methodological basis of the present work is founded on the theory of metaphor modeling. The following system of methods is used: linguo-cultural, componential, contextual and stylistic analysis. The research made it possible to conclude that metaphors are an important means of reflecting the new knowledge about the pandemic situation. The pandemic theme is a popular object of metaphorization in the texts of contemporary German media. COVID-19 is represented as an active force, interacting and communicating with people, and leading in the said interaction. It is represented as an enemy; thereby the metaphors of fighting and war describe the opposition of the coronavirus and the humanity.

(C) Шаманская М. А., 2021

Контент доступен под лицензией Creative Commons Attribution 4.0 License.

The content is available under Creative Commons Attribution 4.0 License. 
The disease is also used as a source domain for metaphors representing various modern facts of importance. The research of the metaphorical component in the description of current pandemic situation can contribute to the comprehending the ways in which language helps to conceptualize the reality.

Key words: metaphor, mass media, German mass media, pandemic, coronavirus, COVID-19.

\section{Введение}

Исследование метафорической репрезентации действительности востребовано в современной лингвистике, поскольку метафора понимается как инструмент познания. Словами Дж. Вико, метафора - это «узел, связывающий язык с мышлением и культурой» [цит. по: 1, с. 248]. Таким образом, изучение метафор позволяет исследователю приблизиться к пониманию того, как знание о мире находит свое отражение в языке, причем с включением в область понимания национально-культурной специфики. При метафоризации происходит осмысление сложных и неструктурированных сущностей в более конкретных формах [2, с. 10]. Процесс осмысления значительно упрощается наглядным характером метафоры. Как отмечает В. Н. Телия, в ее основе лежит «допущение о подобии, приводящее в динамическое состояние знание о мире, образно-ассоциативное представление, вызываемое этим знанием, и уже готовое значение, которые и взаимодействуют в процессе метафоризации» $[1$, c. 15]. Соответственно, метафорический образ в своей конкретности удобен для обработки и представления информации.

Актуальность изучения метафор в этом аспекте возрастает в периоды общественных потрясений, когда новое знание о мире ищет пути своего выражения в языке. А. Н. Баранов говорит о связи метафоры с «кризисным» мышлением: количество метафор в исследуемых корпусах текстов увеличивается в переломные моменты истории [3]. Интерес к этой стороне метафорического творчества характеризуется рядом работ последних десятилетий. Так, исследуются метафоры, применяющиеся для описания военных конфликтов [4], кризисных явлений в экономике [5], миграционного кризиса в Европе [6]. Распространение коронавирусной инфекции в 2020 г. оказало существенное влияние на социально-экономическую ситуацию во всем мире, спровоцировав кризис экономики во многих странах и значительно повлияв на организацию повседневной жизни людей. Появились публикации, посвященные отражению осмысления этих событий в русском [7] и других языках [8]. В данной работе мы сосредоточены на рассмотрении метафорической репрезентации темы коронавирусной инфекции в немецких СМИ.

\section{Материалы и методы исследования}

Объектом данного исследования служат метафоры, использующиеся при описании пандемии
COVID-19 в немецкоязычном медиадискурсе. Материалом работы послужил корпус отобранных методом сплошной выборки публикаций электронного издания «Spiegel Online» за первую половину 2020 г. общим объемом 103 текста [9]. Выбор названного издания обусловлен его авторитетностью и популярностью в немецком новостном пространстве. Издание публикует новостные сообщения, отражающие актуальнейшие тенденции развития общественной ситуации в стране и мире, а также авторские аналитические обзоры. Мы полагаем, что изучение средств языковой репрезентации действительности, представленных в указанных типах текстов, позволяет выявить особенности восприятия обществом нового и значимого явления - пандемии коронавируса. При этом мы пытаемся установить, действительно ли метафора играет значимую роль в этом процессе.

Методология исследования основана на теории метафорического моделирования, рассматривающей связи между понятийными сферами-источниками и сферами-мишенями. В целях более точного и однозначного изложения мы пользуемся терминами С. А. Хахаловой: «фиктивный денотат» для обозначения элемента сферы-источника и «реальный денотат» для обозначения элемента сферы-мишени [10]. При метафорическом переносе в сознании актуализируется комплекс знаний и представлений о фиктивном денотате, который транслируется на денотат реальный и служит его характеристике (и оценке). Метафорические модели как виртуальные сущности находят свое выражение в языке в качестве языковых метафор, доступных лингвистическому анализу. Для выявления особенностей метафорической репрезентации тематики пандемии в рассматриваемых текстах применяются метод лингвокультурного анализа, метод компонентного анализа, метод контекстуального и стилистического анализа.

\section{Обсуждение результатов}

В настоящей работе рассматриваются примеры, в которых для наименования реального денотата используются слова Coronavirus (Corona) (78 случаев употребления в рассматриваемых текстах) и Coronakrise (40 случаев употребления). Мы видим, что для обозначения болезни употребляется название ее возбудителя - вируса. Отмечается также использование слова «возбудитель» - Erreger (4 случая употребления). Кроме того, с точки зрения влияния на общественную жизнь трудно разделить само явление 
пандемии и вызванные пандемией последствия, соответственно, мы не проводим строгого разграничения этих явлений.

Как показывает анализ материала, в публикациях, посвященных распространению коронавирусной инфекции, акцентуируются различные аспекты восприятия этого явления. Так, в текстах, информирующих читателя о новой болезни и описывающих ее свойства, вирус репрезентируется как враг: Der Erreger ist immer der «Feind von außen» («Schon Robert Koch beschrieb Erreger als Feinde», 15.04.2020). Возбудитель болезни внедряется в человеческий организм, однако он ассоциируется с внешним врагом. Так выстраивается модель противостояния человека и враждебной силы. Хотя вирус как таковой лишен моральных качеств, в этой модели он становится носителем зла: Die Faszination des unsichtbaren Bösen (15.04.2020). В приведенном примере инфекция представлена как само зло, т. е. здесь происходит специфический метафорический перенос, где реальный денотат (болезнь и ее возбудитель) более конкретен, чем фиктивный денотат (зло). Так негативное воздействие пандемии абсолютизируется, а страх перед нею нагнетается: зло невидимо, а потому более опасно. Абсолютизация наблюдается и в следующем примеpe, где пандемия называется «бедствием библейского масштаба»: In Zeiten, in denen Kranke allein sterben und die Menschheit im Griff einer Plage biblischen Ausmaßes ist, sehnen sich viele nach Trost (Ostern in der Coronakrise. Was uns jetzt Kraft gibt, 10.04.2020). Отсылка к прецедентному тексту (Библии) усиливает зловещую значимость образа COVID-19, а все человечество репрезентировано как жертва бедствия, находящаяся в его «хватке». В противопоставлении человечества и болезни именно болезнь выступает как более сильный «партнер». Мистическая составляющая образа коронавируса особенно явно проявляется в первых сообщениях о появлении и распространении инфекции. Для них характерно употребление эпитетов со значениями «новый», «неизвестный»: ...das bis kurz zuvor unbekannte Coronavirus (Neues Coronavirus, 22.01.2020). Вариациями таких эпитетов являются слова «загадочный» и «необычный» (mysteriös, unheimlich): Erster Todesfall nach Ausbruch von mysteriöser Lungenkrankheit (11.01.2020); Seuchenexperten rätseln über Coronavirus. Der unheimliche Erreger 2019-nCoV (24.01.2020). Нами выявлено 11 случаев употребления подобных имен прилагательных в 7 текстах. Таким образом, коронавирусная инфекция репрезентируется как некая загадочная сущность, чье появление неожиданно для специалистов, вынужденных строить догадки (rätseln) относительно ее. Несомненно, акцентуация таких признаков, как «новизна» и «необычность», в текстах прессы призвано пробудить интерес читателей, однако можно допу- стить, что в данном случае она также отражает особенности восприятия обществом новой и опасной болезни, о которой даже экспертам известно очень мало.

Следующий параметр, который можно выделить в публикациях на тему коронавирусной инфекции, - это ее воздействие на общество. Поскольку коронавирус представлен в качестве врага человека, то и последствия его распространения репрезентируются как некие «действия», что подчеркивается использованием слов «вирус» и «пандемия» в качестве подлежащего в предложениях, описывающих ситуацию в обществе. Так, пандемия «ставит под угрозу доход самозанятых»: Die Corona-Pandemie bringt viele Selbstständige in Existenznot (Diese Selbstständigen haben jetzt mehr Aufträge, 15.04.2020). Вредоносное воздействие COVID-19 затрагивает различные сферы. Инфекция смертоносна для людей, и это качество служит основой для метафорического переноса в следующем примере, где коронавирус именуется «убийцей культуры»: Kulturkiller Corona (03.04.2020). «Действия» кризиса направлены если не на уничтожение, то на ограничение, сокращение обычной активности. Так, он сокращает наполовину число бронирований в отелях: Die Coronakrise hat die Zahl der Hotelübernachtungen im März im Vergleich zum Vorjahresmonat mehr als halbiert (53 Prozent weniger Gästeübernachtungen im März, 08.05.2020). В следующем примере речь идет о введенных правительством правилах социального дистанцирования и самоизоляции, но буквально говорится о том, что именно кризис замедляет нормальный ход жизни: Die Coronakrise lähmt das Leben in Deutschland (Ostern in der Coronakrise. Ein bisschen Hoffnung, 09.04.2020). Таким образом, даже ограничительные меры, направленные на сдерживание распространения болезни, представлены как результат проявления ее «инициативы».

Одной из наиболее примечательных особенностей метафорического представления коронавируса в рассматриваемых текстах является репрезентация его воздействия на людей как своеобразных «взаимоотношений». При этом инициатором отношений выступает именно COVID-19, его активная роль постоянно подчеркивается. В условиях пандемии людям приходится менять привычный образ жизни, подстраиваться под изменившуюся ситуацию. При констатации этого факта именно вирус представлен как действующее лицо, он «определяет жизнь» человека: Virologe Martin, 31: Wie Corona sein Leben bestimmt (14.04.2020). В следующем примере говорится об изменении личных планов конкретного человека, когда он не может увидеться с родственниками из-за обострившейся эпидемиологической ситуации. Эти обстоятельства также представлены как результат активного действия коронавируса, откладывающего 
встречу: Karim wartet seit Jahren auf seine Familie Corona verzögert das Wiedersehen auf unbestimmte Zeit (03.05.2020). Можно утверждать, что в приведенных примерах наблюдается эффект максимального снижения уровня абстракции при конструировании образа реального денотата. Он выступает в качестве контрагента в общении с конкретными людьми, оказывая непосредственное влияние на их жизнь. Это очень личное общение, при котором дистанция между участниками минимальна. Идет ли речь о людях, не наделенных властью, или о президенте России, коронавирус проявляет инициативу в установлении контакта, направленного на разрушение планов партнера: Das Virus verdirbt die Pläne des russischen Präsidenten, sich die Macht für ewig zu sichern (Warum Corona für Putin ein perfekter Sturm ist, 01.05.2020).

Агрессивность вируса как «партнера во взаимоотношениях» подчеркивается употреблением глагола treffen «поражать». Цели коронавируса, т. е. попадающие под его удар субъекты, весьма разнообразны: от населения целых городов до отдельных людей: Warum Covid-19 New York so viel härter getroffen hat als Hongkong (07.05.2020); Das Coronavirus trifft nicht zwingend alle Mitglieder eines Haushalts (Risikofaktor Familie, 07.05.2020). Таким образом, заражение болезнью репрезентируется как следствие ее «нападения». При этом вирусу приписывается такое качество, как избирательность, способность действовать по своему усмотрению. В следующем примере примечательно употребление глагола verschmähen «отвергать»: Wenn das Virus den Partner verschmäht (07.05.2020). Так выстраивается образ реального денотата как существа, наделенного свободой воли и проявляющего ее в отношениях с людьми: он может «выбирать» своих жертв либо «отвергать» их. В такой модели взаимодействия человек является зависимым, более слабым партнером.

Метафоризация способов реагирования на болезнь со стороны людей связана с метафорическим представлением пандемии как врага. Так, при описании санитарно-эпидемиологических мер говорится о «защите от COVID-19»: Wo sind die Menschen am besten vor Covid-19 geschützt? (Im Ländervergleich liegt Deutschland sehr weit vorn, 14.04.2020). Люди, перенесшие болезнь, «сопротивляются» ей: Sie überlebte zwei Weltkriege und trotzte nun einer Covid-19-Infektion (106-jährige Britin übersteht Corona-Infektion, 15.04.2020). В условиях противостояния врагу закономерно использование такого глагола, как bewältigen «справляться с чем-л.»: Wie sich die Coronakrise auf effiziente Weise bewältigen lässt (11.04.2020). Мы видим, что модель «отношений» человечества и коронавируса бинарна: с одной стороны - обороняющееся общество, с другой - угрожающий ему враг. Меры по противодействию распространению инфекции именуются борьбой: Abstand halten lautet das oberste Gebot im Kampf gegen Corona (Politiker-Lapsus in Uniklinik. Voll daneben, 14.04.2020). Модификацией метафоры борьбы с COVID-19 является военная метафора, которая выражается употреблением лексем соответствующей тематической группы («второй фронт»): Die zweite Front im Kampf gegen das Coronavirus (18.02.2020). Метафора «борьба против распространения коронавируса - война» является распространенной, что показывает частотность выражения Corona-Krieg в поисковых системах: Die Wortkoppelung «Corona-Krieg》liefert schon etwa 4000 Suchmaschinentreffer (Das hier ist kein Krieg, 02.04.2020).

При репрезентации тематики пандемии и мер противодействия ей используется также пространственная метафора. Текущая ситуация представлена в качестве некоего пространства, причем пространства замкнутого. Введенные весной 2020 г. карантинные меры, ограничивающие передвижение и контакты людей и вынуждающие их буквально оставаться в помещении, служат источником этого метафорического образа: Coronavirus. Wege aus dem Lockdown in Israel (14.04.2020). Так ограничительные меры выступают в качестве изолированного участка, а меры по решению проблемы пандемии - как выход за его пределы: NRW-Ministerpräsident Armin Laschet hat Experten beauftragt, Wege aus den Corona-Beschränkungen zu suchen (Corona-Maßnahmen in NRW. Beraterstab stellt Reihenfolge zum Wiederhochfahren der Wirtschaft vor, 11.04.2020). В данном случае на пространственную метафору накладывается метафора движения: позитивная динамика развития ситуации обозначается словом Wege «пути выхода», что подразумевает перемещение за пределы закрытого пространства. Движение предполагается также в примеpe с использованием слова Rückkehr «возвращение (к обычному образу жизни)»: Niedersachsen probt die Rückkehr zum Alltag (04.05.2020). Таким образом, пандемия выступает в качестве ограничителя пространства и движения, а улучшение ситуации - в качестве движения за пределы ограничений.

Одним из наиболее примечательных, на наш взгляд, параметров метафоризации тематики коронавируса является осмысление людьми новых социально-политических условий, т. е. психологический аспект пандемии. В этом случае метафорически представлены уже не меры, предпринимаемые для противодействия инфекции, но особенности восприятия и оценки событий людьми. Чрезвычайная ситуация, вызванная распространением болезни, сравнивается с тестом, испытанием для общества и политических систем: Die Coronakrise ist ein Stresstest für unsere Gesellschaft (03.04.2020). При этом подчеркивается активная роль кризиса, он является не просто 
испытанием, но и действующим лицом, которое ставит перед организациями новые вызовы и вопросы: Die Coronakrise stellt die Nato vor ungeahnte Herausforderungen (Das Virus erfasst die Nato (01.04.2020). В условиях пандемии происходит переоценка ценностей и подвергаются сомнению установившиеся отношения между гражданами, политическими силами и правительством. Коронавирус при этом представлен как некая веха, например, отмечающая конец успеха партии Зеленых в Германии: Markiert Corona das Ende des grünen Höhenflugs? (Grüne in der Corona-Pandemie. Hoffen auf den Aufschwung nach der Krise, 13.04.2020). Примечательно то, что перераспределение сил представлено как результат действий со стороны вызванного коронавирусом кризиса: Die Coronakrise stellt das Verhältnis von Bürgern und Regierung infrage (Die neue Normalität der Unsicherheit, 15.04.2020). Таким образом, коронавирус выступает в качестве инициатора общественных процессов. В кризисное время закономерно усиление некоторых экономических и социальных факторов и ослабление других, однако этот факт описывается как проявление активных действий со стороны пандемии или кризиса, что выражается употреблением глаголов со значениями «усиливать» (verstärken) или «ускорять» (beschleunigen). Так, например, пандемия «усиливает уже существующие тенденции»: Die Corona-Pandemie verstärkt Trends, die seit Jahren zu beobachten sind (Wirtschaftliche Folgen der Corona-Pandemie. Die Welt nach der Krise, 12.04.2020). Кризис «ускоряет процесс внедрения цифровых технологий»: Arbeit, Bildung, Wirtschaft, Sozialleben: Die Coronakrise beschleunigt die Digitalisierung wichtiger Gesellschaftsbereiche (Coronakrise. Die neue digitale Elite, 11.04.2020). Следует отметить, что в аналитических обзорах о влиянии коронавируса на общество подчеркивается важность осуществляющихся перемен, которые затрагивают ключевые сферы жизни: трудовые отношения, образование, экономику, социальные контакты.

Воздействие COVID-19 на общество двояко. C одной стороны, что вполне закономерно, наблюдается негативная оценка влияния пандемии на социальную структуру и человеческие взаимоотношения. Поскольку кризис способствует расслоению общества, говорится о том, что «пандемия разделяет людей»: Die Corona-Pandemie spaltet die Menschen (Britischer Politologe über Corona-Folgen. «Wir können unsere gute, alte Demokratie nicht retten», 12.04.2020). При этом пандемия репрезентируется как враг, угрожающий демократии, которая нуждается в спасении. С другой стороны, глобальная угроза выступает как фактор консолидации общества. Die Coronakrise offenbart das Solidaritätspotenzial unserer Gesellschaft (Folgen der Coronakrise. Der Schuldenberg des Vertrau- ens, 10.04.2020). Отметим, что использование в последнем примере глагола offenbaren «проявлять/показывать» приписывает кризису способность выступать в качестве своеобразного «партнера по коммуникации» по отношению к людям: он играет активную роль в осознании необходимости солидаризации.

В свою очередь, понятийная область болезни служит сферой-источником для медицинской метафоры. Актуальность тематики болезни, здоровья и лечения делают ее благодатной средой для метафорического творчества. В первую очередь это касается репрезентации явлений, напрямую связанных с пандемией. Так, метафорически представлено восприятие болезни обществом. Лексемы Fieber «лихорадка», Pandemie «пандемия» используются при описании реакции общественности на новости о коронавирусе: Die Gerüchte-Pandemie (30.01.2020), Deutschland im Corona-Fieber (05.02.2020). В этом случае фиктивным денотатом выступает сама болезнь, чьи качества (опасность, заразность и быстрота распространения) прекрасно подходят для характеристики эмоций аудитории. Реальным денотатом является страх (Angst) / паника (Panik) перед новостями о болезни. Наиболее частотными глаголами, служащими для конструирования медицинской метафоры в данном контексте, являются глаголы со значением «заражать»: anstecken, infizieren: Wenn Angst vor dem Coronavirus die ganze Welt ansteckt (02.02.2020), Die Angst vor der neuen Lungenseuche infiziert die Börsen (28.02.2020). Так распространение страха перед болезнью уподобляется самой болезни. Отметим, что в последнем примере идет речь уже о влиянии страха перед коронавирусом не только на массовое сознание, но и на экономику.

Экономика, наряду с массовым сознанием, является еще одной сферой-мишенью медицинской метафоры. Так, экономическая рецессия именуется вирусом: Das Pleitevirus frisst die deutsche Wirtschaft (03.04.2020). Меры по исправлению положения описываются как «оказание первой помощи», «финансовая прививка/укол»: Erste Hilfe gegen die CoronaRezession (28.02.2020), Impfstoff für die Börse (03.03.20), Mit Finanzspritzen gegen das Virus (03.03.20). Предприятия могут репрезентироваться как живой организм, их благополучное экономическое положение - как хорошее состояние здоровья: «Wir werden verhindern, dass wirtschaftlich gesunde Unternehmen in die Insolvenz geraten» (13.03.2020).

Медицинская метафора распространяется на разные понятийные сферы. Употребление в различных контекстах таких слов, как «вирус» или «эпидемия» в текущей ситуации вызывает ассоциацию с определенной болезнью - коронавирусной инфекцией. Эта ассоциация активно используется для характеристики негативных общественных настроений или разрушительной идеологии. В следующем примере 
автор апеллирует к знанию читателя о «первом вирусе», т. е. коронавирусе, вводя тему национализма, который он называет «вторым вирусом». Так объединяются представления о реальном и фиктивном денотате: Das zweite Virus heißt Nationalismus (16.04.2020). Метафора «национализм - это болезнь» не является новой в политическом дискурсе, однако в условиях пандемии она приобретает остроту, необходимую автору для выражения отрицательной оценки. Таким образом, негативные явления в экономике, политике, общественном сознании соотносятся не просто с некоторым обобщенным представлением о болезни, но с представлением именно о коронавирусе. Это позволяет автору усилить негативную оценку осуждаемых им явлений. Этот прием мы наблюдаем в следующем примере, где объектом осуждения являются действия президента Бразилии. Значение слова Hass «ненависть», уже негативно-оценочное, усиливается ассоциацией, вызываемой уподоблением вирусу: Jair Bolsonaro demontiert Brasiliens Demokratie. Das Virus seines Hasses (02.05.2020).

Объекты (не только экономические), подвергающиеся опасности или нуждающиеся в заботе, репрезентируются как живой организм, подверженный болезни. В качестве «больного» может выступать, например, город: Eine Stadt erwacht aus dem Koma (10.04.2020). Меры, направленные на улучшение положения, или же просто приятные для человека явления соотносятся с защитными системами организма или лечением. В следующем примере весь мир представлен как организм, подвергающийся угрозе заболеть, а социальные сети, помогающие поддерживать личные контакты в условиях отказа от непосредственного общения - как его иммунная система: In der Coronakrise finden soziale Medien ihre Rolle als informationelles Immunsystem der Welt (Coronavirus und soziale Medien. TikTok-Tänze retten plötzlich Menschenleben, 11.03.2020). Лексема impfen «прививать» используется в контексте противодействия любым отрицательным явлениям, таким как варварство в следующем примере: Impft euch gegen das Virus der Barbarei! (03.04.2020).

Примечательно то, что медицинские термины используются для метафоризации не только негативно оцениваемых явлений: Wir brauchen eine Epidemie der Empathie (29.03.2020). Выражение «эпидемия эмпатии» обязано своим появлением исключительно актуальности слова «эпидемия». Здесь реальный и фиктивный денотаты не только соотносятся, но и противопоставляются: негативная оценка такого явления, как эпидемия, сталкивается с позитивным представлением об эмпатии, на которое проецируется качество «быстрота распространения». Можно сделать вывод, что в ситуации пандемии медицинская метафора стала популярной для описания различных сфер жизни.

\section{Заключение}

Анализ материалов исследования показал, что тема пандемии коронавируса подвергается активной метафоризации в немецких СМИ. Очевидно, метафора является важным инструментом выражения и распространения информации о новом социально значимом явлении, поскольку позволяет осмыслить новое знание в терминах уже существующих понятийных областей. Кроме того, метафора помогает сформировать эмоционально-оценочное мнение о реальном денотате, что также весьма существенно, когда речь идет о факторах, затрагивающих все стороны жизни общества.

В статьях, целью которых является информирование населения о распространении инфекции и характеристика нового на тот момент заболевания, актуализируется метафора «коронавирус - это враг». Рассмотренные примеры конструируют образ коронавирусной инфекции как врага, пришедшего извне и проявляющего агрессию по отношению как к людям (отдельным личностям и обществу в целом), так и к творениям человека: культуре и экономике. В текстах эта метафора реализуется употреблением для обозначения болезни таких лексем, как der Feind, das Böse, der Killer. Способность болезни вызвать смерть человека метафорически переносится на различные сферы. В аналитических обзорах, освещающих влияние пандемии на социально-экономическую ситуацию, COVID-19 приписывается инициатива в противостоянии людям, а негативные результаты распространения инфекции представлены как результат активных действий врага. Этот эффект достигается использованием таких глаголов, как treffen, lähmen, verderben. В этом контексте актуализируется метафора «противодействие распространению инфекции - это борьба», в том числе одна из ее модификаций: «противодействие распространению инфекции - это война». С борьбой соотносятся как меры, предпринимаемые правительствами для ограничения инфекции, так и выздоровление отдельных людей, перенесших болезнь. Способы реагирования на болезнь со стороны больных, врачей и властей представлены такими лексемами, как der Kampf, der Krieg, die Front, trotzen, bewältigen, schützen.

Примечательным является то, что коронавирус представлен в качестве инициатора различных общественных процессов, например, распространения цифровых технологий, а также расслоения общества или, наоборот, его консолидации. Так, при реализации метафоры «коронавирус - это тест/испытание» используются такие лексемы, как der Test, die Herausforderung.

Кроме того, актуальность медицинской тематики обусловила использование медицинской метафоры в различных контекстах, как зависимых от пандемии (распространение в обществе страха перед инфекцией или экономическая рецессия, вызванная пандеми- 
ей), так и напрямую не связанных с ней (идеология национализма). Отмечаются случаи использования метафор «страх - это болезнь», «экономическая рецессия - это болезнь», «национализм - это болезнь», «предприятие - это организм», «мир - это организм».

В заключение можно утверждать, что процесс метафоризации явлений, связанных с пандемией, находится в активной фазе, и в дальнейшем могут ожидаться как пополнение уже сложившихся метафорических моделей новым языковым материалом, так и создание новых моделей.

\section{ЛИТЕРАТУРА}

1. Телия В. Н. Русская фразеология. Семантический, прагматический и лингвокультурологический аспекты. М. : Школа «Языки русской культуры», 1996. 288 с.

2. Лакофф Дж., Джонсон М. Метафоры, которыми мы живем / под ред. и с предисл. А. Н. Баранова. М. : Едиториал УРСС, 2004. $256 \mathrm{c.}$

3. Баранов А. Н. Дескрипторная теория метафоры. М. : Языки славянской культуры, 2014. 632 с.

4. Шарманова О. С. Метафора, метонимия, метафтонимия. Способы концептуализации грузино-российского конфликта (на примере немецкоязычных СМИ) : дис. ... канд. филол. наук. Иркутск, 2012. 202 с.

5. Бадаева Н. В. Механистическая метафора в экономическом дискурсе немецкоязычных масс-медиа в период кризиса 2008-2011 гг. // Филологические науки в МГИМО. 2018. № 1 (13). С. 5-11.

6. Розе Е. Е., Емельянов А. В. Метафоры в миграционном дискурсе англоязычных газетных статей // Ученые записки Новгород. гос. ун-та. 2018. № 4 (16). С. 9-12.

7. Темиргазина 3. К. Вспышка, всплеск или волна : как и что мы говорим о коронавирусе // Неофилология. 2020. T. 6, № 24. С. 645-652.

8. Wicke P., Bolognesi M. M. Framing COVID-19: How we conceptualize and discuss the pandemic on Twitter // PLoS ONE. 2020. № 15 (9).

9. Spiegel Online. URL: https://www.spiegel.de/thema/ coronavirus

10. Хахалова С. А. Метафора в аспектах языка, мышления и культуры. Иркутск : ИГЛУ, 2011. 292 с.

Иркутский государственный университет

Шаманская М. А., кандидат филологических наук, доиент кафедры романо-германской филологии

E-mail:mary-sch@yandex.ru

Поступила в редакциюю 25 января 20212.

Принята к публикации 22 марта 20212.

\section{Для цитирования:}

Шаманская М. А. Метафорическая репрезентация пандемии COVID-19 в текстах немецких СМИ // Вестник Воронежского государственного университета. Серия: Лингвистика и межкультурная коммуникация. 2021. № 2. C. 103-109. DOI: https://doi.org/10.17308/ lic. $2021.2 / 3420$

\section{REFERENCES}

1. Teliya V. N. Russkaya frazeologiya. Semanticheskij, pragmaticheskij i lingvokul'turologicheskij aspekty [Russian Phraseology. Semantic, Pragmatic and Linguoculturological Aspects]. Moscow: Shkola "Yazyki russkoy kultury", 1996. $288 \mathrm{p}$.

2. Lakoff G., Johnson M. Metafory, kotorymi my zhivem [Metaphors We Live By]. Baranov A.N., ed. Moscow: Editorial URSS, 2004. 256 p.

3. Baranov A. N. Deskriptornaya teoriya metafory [Descriptor Theory of Metaphor]. Moscow: Yazyki slavyanskoy kultury, 2014. 632 p.

4. Sharmanova O. S. Metafora, metonimiya, metaftonimiya. Sposoby kontseptualizatsii gruzino-rossijskogo konflikta (na primere nemetskoyazychnykh SMI) [Metaphor, Metonymy, Metaphtonymy. Ways to Conceptualize the Georgian-Russian Conflict (on the Example of German-Language Media)]: Dissertation. Irkutsk, 2012. 202 p.

5. Badaeva N. V. Mekhanisticheskaya metafora v ehkonomicheskom diskurse nemetskoyazychnykh mass-media v period krizisa 2008-2011 gg. [Mechanistic Metaphor in the Economic Discourse of German-Language Media During the Crisis of 2008-2011]. In: Filologicheskie nauki v MGIMO. 2018. No. 1 (18). Pp. 5-11.

6. Roze E. E., Emelyanov A. V. Metafory v migratsionnom diskurse angloyazychnykh gazetnykh statej [Metaphors in the migration discourse of English newspaper articles]. In: Uchenye zapiski Novgorodskogo gosudarstvennogo universiteta. 2018. No. 4 (16). Pp. 9-12.

7. Temirgazina Z. K., Vspyshka, vsplesk ili volna: kak i chto my govorim o koronaviruse [Outbreak, surge or wave: how and what we say about the coronavirus]. In: Neofilologiya. 2020. Vol. 6, No. 24. Pp. 645-652.

8. Wicke P., Bolognesi M. M. Framing COVID-19: How we conceptualize and discuss the pandemic on Twitter. In: PLoS ONE. 2020. No. 15 (9).

9. Spiegel Online. Available at: https://www.spiegel.de/ thema/coronavirus

10. Khakhalova S. A. Metafora $v$ aspektakh yazyka, myshleniya i kul'tury [Metaphor in the Aspects of Language, Thinking and Culture]. Irkutsk: IGLU, 2011. 292 p.

\section{Irkutsk State University}

Shamanskaya M. A., Candidate of Philology, Associate Professor of the Roman and German Philology Department E-mail: mary-sch@yandex.ru

Received: 25 January 2021

Accepted: 22 March 2021

\section{For citation:}

Shamanskaya M. A. Metaphorical representation of the COVID-19 pandemic in German mass media texts. Proceedings of Voronezh State University. Series: Linguistics and Intercultural Communication. 2021. No. 2. Pp. 103-109. DOI: https://doi.org/10.17308/lic.2021.2/3420 